\title{
Antrochoanal Polyp Recurrence-free Management: Our Experience
}

${ }^{1}$ Venkatesh M Patil, ${ }^{2}$ Rashmi M Patil, ${ }^{3}$ Vinayak V Rayakar, ${ }^{4}$ Ravindrakumar N Karadi

\begin{abstract}
The terminology "antrochoanal polyp" emerged from nasal polyp only when Killian in 1906 noted the antral connection of this polyp. Hence, it is also known as Killian's polyp. Many surgical techniques are described for the management of antrochoanal polyp: (1) Killian's avulsion of pedicle of polyp; (2) Caldwell-Luc surgery; (3) endoscopy sinus surgery.

When polyp origin is broadly based or when base is located at unfavorable portion, such as anterior/inferior portion of maxillary sinus, recurrence occurs due to retention of diseased mucosa carrying mucous cyst.

Propensity of polyp to recur after various methods of treatment has led to the development of a technique that causes least recurrence. A technique that prevents recurrence will be the best one.
\end{abstract}

Keywords: Antrochoanal polyp, Endoscopic sinus surgery, Mini Caldwell-Luc, Recurrence.

How to cite this article: Patil VM, Patil RM, Rayakar VV, Karadi RN. Antrochoanal Polyp Recurrence-free Management: Our Experience. Int J Otorhinolaryngol Clin 2018;10(1):4-10.

Source of support: Nil

Conflict of interest: None

\section{INTRODUCTION}

Killian's polyps are usually unilateral and occur most commonly in pediatric age group and in young adults. About 4 to $6 \%$ of all nasal polyps are antrochoanal polyps, which are more common in males than females. ${ }^{1}$ Antrochoanal polyp arises from inflamed and edematous mucosa of the maxillary antrum. It consists of two components: (1) antral one, which is mostly cystic and (2) nasal part, which is solid. The site of attachment is either through the natural maxillary sinus ostium or an accessory one. Surgery is the main line of treatment. A combination of Mini Caldwell-Luc and functional

\footnotetext{
${ }^{1,2}$ Assistant Professor, ${ }^{3}$ Fellow, ${ }^{4}$ Professor and Head

1,3,4 Department of Otorhinolaryngology, Shri B. M. Patil Medical College, BLDE University, Bijapur, Karnataka, India

${ }^{2}$ Department of Surgery, Shri B. M. Patil Medical College, BLDE University, Bijapur, Karnataka, India

Corresponding Author: Venkatesh M Patil, Assistant Professor Department of Otorhinolaryngology, Shri B. M. Patil, Medical College, BLDE University, Bijapur, Karnataka, India, Phone: +919731467014, e-mail: venkat27mp@rediffmail.com
}

endoscopic sinus surgery (FESS) helps in complete removal of disease, with absence of recurrence.

\section{AIM}

To do the clinical study of etiopathology of antrochoanal polyp and effectiveness of management using the combination of Mini Caldwell-Luc and endoscopic sinus surgery.

\section{MATERIALS AND METHODS}

This is a prospective, randomized, observational study. The symptomatological, diagnostic, and therapeutical perspectives of 20 patients, who had their antrochoanal polyp operated and were followed at the Department of Otorhinolaryngology, BLDE's Shri B. M. Patil Medical College Hospital between July 2012 and January 2014 were analyzed in this study.

\section{Inclusion Criteria}

Patients with antrochoanal polyp picked out from otolaryngological surgical admissions of common nasal polyps; 11 male patients and 9 female patients (total 20 cases), with antrochoanal polyp diagnosed by means of clinical examination, $X$-ray paranasal sinus, nasal endoscopy and computed tomography (CT) scan, surgical findings were included in the study.

\section{Exclusion Criteria}

All cases of polypiodal mass other than antrochoanal polyp diagnosed by clinical, radiological, and histopathological investigations were excluded from the study.

\section{Study Design}

Twenty cases of antrochoanal polyp were selected; the data were collected and analyzed in terms of details of history, clinical examination, radiological finding, and preoperative, operative, and postoperative finding.

Patients with antrochoanal polyp had CT scans, which was performed in both axial and coronal planes to image the entire nasal cavity and nasopharnyx.

In all patients, Mini Caldwell-Luc and endoscopic sinus surgery was done. They were operated under general anesthesia. During surgery 0 and 45 Hopkins telescopes were used. 
In children, we made an inspection hole on canine fossa, which measured $<1 \mathrm{~cm}$. The antral component was elevated by curved elevators with visual guidance through endoscopy. The nasal component is gently mobilized at the pedicle. Endoscopic antrostomy of maxillary ostium helped us to deliver the antrochoanal polyp en bloc. In adults we approached the antrum by a bigger opening than that of children.

Histological preparations of the surgical specimens were examined to determine the histological characteristic of antrochoanal polyp.

Cases were postoperatively followed for a period ranging from 5 to 30 months and the surgical results were assessed pertaining to relief from symptoms and to frequency of recurrence.

\section{OBSERVATIONS}

\section{Epidemiology}

In our observations of 20 patients, 11 were males and 9 females, i.e., $55 \%$ were males and remaining females. Patients were from age group 10 to 50 years, with youngest patient of 12 years and oldest patient of 48 years, with maximum number of patients in age group 10 to 20 years $(\mathrm{n}=9)$. Out of 20 cases of antrochoanal polyp, 15 cases $(75 \%)$ had right-sided disease and 5 cases $(25 \%)$ had leftsided disease.

The common complaints of the patients were nasal obstruction followed by purulent nasal discharge. Three patients suffered recurrent epistaxis. The duration between onset of symptoms and referral to hospital varied from 3 weeks to 4 years. Two patients had recurrent polyps after simple polypectomy at other clinics (Graph 1).

Antrochoanal polyp was clearly seen in anterior rhinoscopy in 18 patients. In two patients, discovery was made during nasal endoscopy. Five patients had ipsilateral hypertrophied inferior concha, 10 had deviated nasal septum, and 1 patient had adenoid hypertrophy. In three cases, antrochoanal polyps were sufficiently large to be seen obviously at oropharyngeal examination.

All CT scan examinations were suggestive of antrochoanal polyp. On scan examination, 10 patients had septal deviation, 3 patients had isolated antrochoanal polyp, while in 5 patients diffuse polyposis was seen. Six patients with antrochoanal polyps were associated with ipsilateral ethmoidal sinusitis. Conchum bullosa was accompanying antrochoanal polyp in 8 patients. Paradoxical middle turbinate was present in 1 patient (Graph 2).

In two cases with recurrence of antrochoanal polyp, middle turbinate was absent due to excision in previous surgery. In 12 patients, antrochoanal polyp was originating from accessory ostium, while in 8 patients, antrochoanal polyp had grown through the natural ostium (Table 1). In all 20 patients, Mini Caldwell-Luc and endoscopic sinus surgery was done. Twelve cases underwent middle meatal antrostomy and uncinectomy, 8 patients had concha bullosa excision and septoplasty, 6 cases underwent anterior ethmoidectomy, 5 patients had posterior ethmoidectomy, and 2 patients had frontal sinus surgery. One case that had adenoid hypertrophy underwent endoscopic-assisted powered adenoidectomy.

The complaints that were seen in the early postoperative period, such as pain, swelling of the cheek, and numbness resolved completely in later follow-up. Out of 20 patients, 18 came for regular follow-up and 2 patients were missed in follow-up. Nasal obstruction which was the main compliant was relieved in all patients. Two patients had synechiae between turbinate and septum, which was later released. No major complaints were noticed in follow-up period. No recurrence was encountered within 5 to 30 months after surgical treatment.

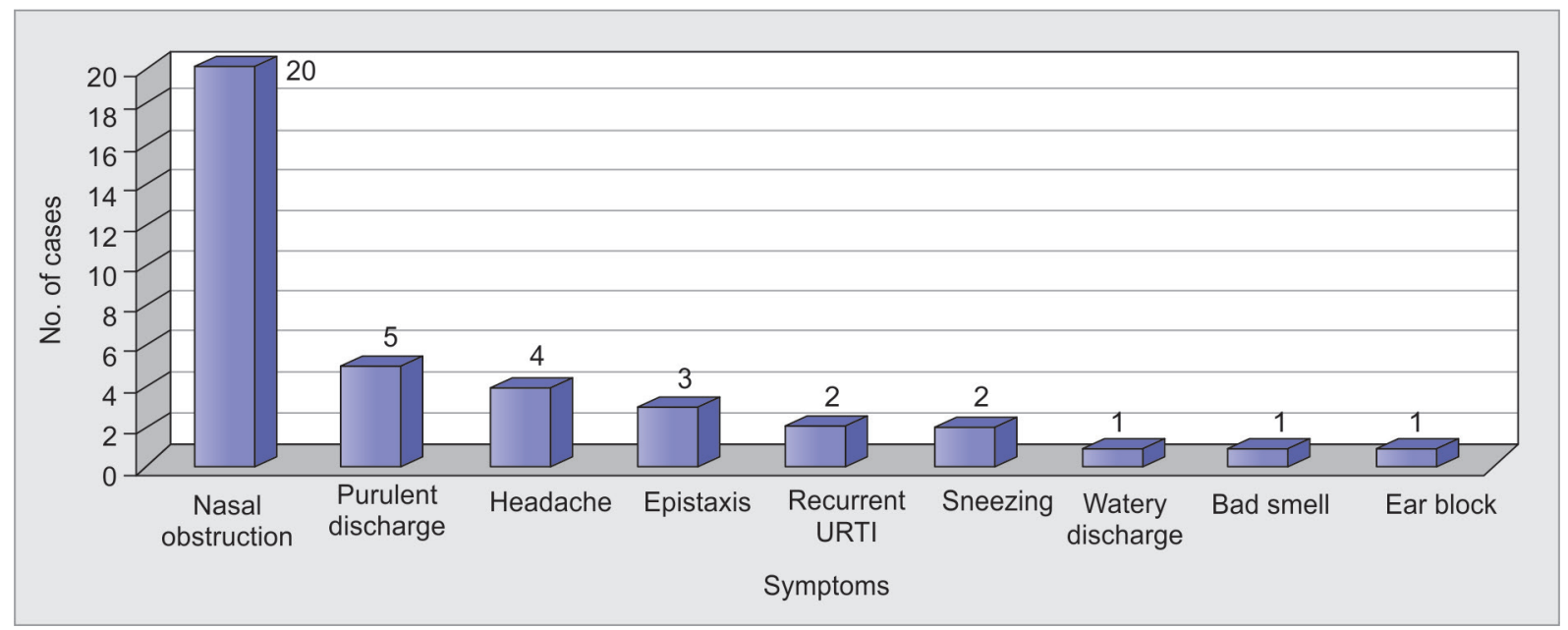

Graph 1: Clinical presentation of case series 


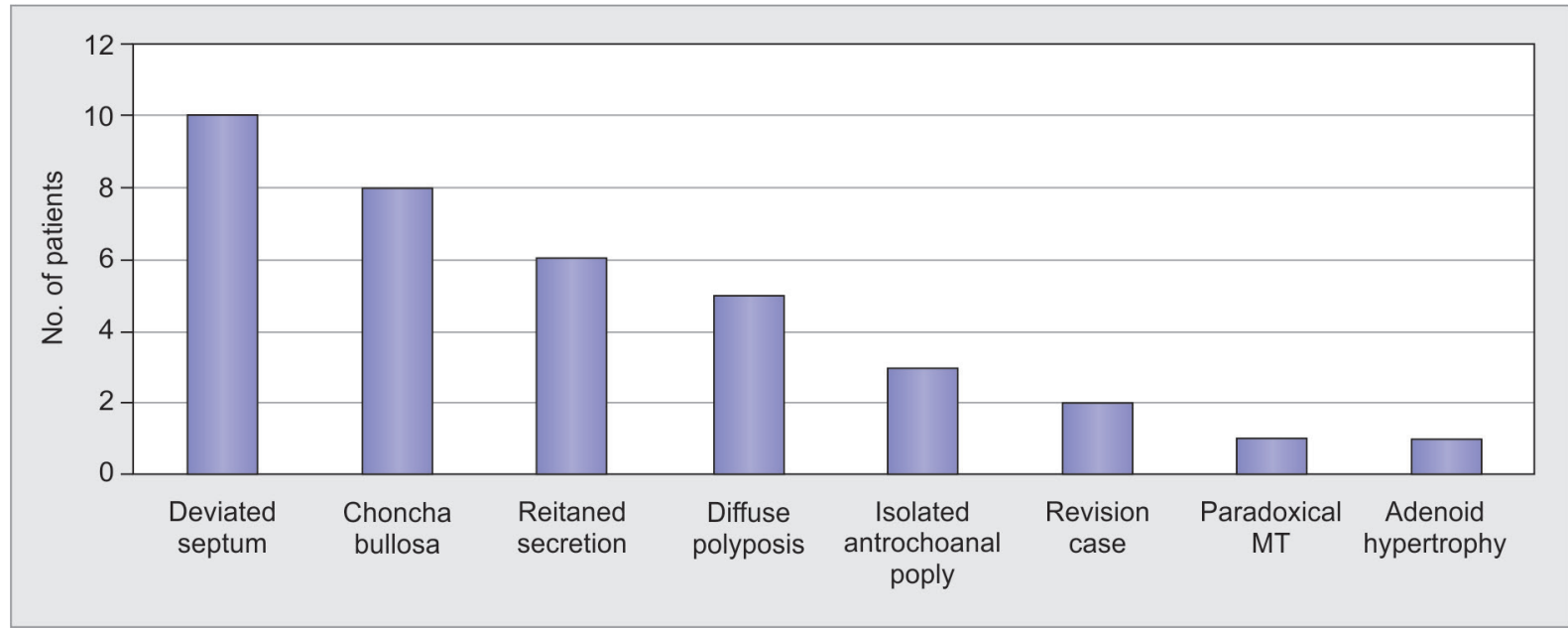

Graph 2: CT scan finding of case series

Table 1: Exit of antrochoanal polyp through natural ostium or accessory ostium

\begin{tabular}{llll}
\hline Studies & $\begin{array}{l}\text { Number of } \\
\text { cases }\end{array}$ & $\begin{array}{l}\text { Natural } \\
\text { ostium (\%) }\end{array}$ & $\begin{array}{l}\text { Accessory } \\
\text { ostium (\%) }\end{array}$ \\
\hline Deka $^{2}$ & 120 & 75 & 25 \\
Özdek et al $^{3}$ & 10 & 70 & 30 \\
Present study & 20 & 40 & 60 \\
\hline
\end{tabular}

\section{DISCUSSION}

Antrochoanal polyp accounts for approximately 4 to $6 \%$ of all polyps in the general population.

\section{Age Incidence}

Antrochoanal polyp is more common in children and young adults.

\section{Site}

The site is usually unilateral and can be easily diagnosed with nasal endoscopy. In those polyps that extend into nasopharynx, one can easily observe the mechanical stress to which these polyps are subjected to during the act of deglutition and talking.

Antrochoanal polyp almost always has two components. A cystic component frequently fills most of the maxillary sinus and the other a solid polypoid part, which extends into middle meatus and nasopharynx ( $80 \%$ of the cases).

The point of origin in the maxillary sinus was almost always from the posterior wall in the vicinity of the maxilloethmoidal angle.

A second point of attachment was found where the stalk of polyp emerged from the maxillary sinus, i.e., at the posterior, inferior part of the exit ostium.

In about $70 \%$ of the patients, the choanal polyp left the maxillary sinus through an accessory ostium in the posterior fontanelle. In only $29 \%$ did the polyp exit the maxillary sinus through the natural ostium.
Exit of antrochoanal polyp is done through natural ostium or accessory ostium. ${ }^{2,3}$ Exit of antrochoanal polyp found through the accessory ostium in $60 \%$ of the cases needed middle meatal antrostomy to join accessory ostium to the natural ostium.

Antrochoanal polyp reaches the middle meatus where it again develops into solid polyp that, as it enlarges, fills the floor of nose and reaches the choana. Depending on size, this intranasal component of polyp may reach the nasopharynx where it may completely obstruct the choana that occasionally becomes visible through the mouth, below free margin of soft palate.

Antrochoanal polyps have high incidence of recurrence unless all of their components have been carefully and completely removed. Recurrence is particularly common when mucosal remnants are allowed to remain at the site of origin.

First manifestation of nasal polyp is a circumscribed or general thickening and swelling of the mucous membrane. The areas of mucosal edema are usually tear shaped for several reasons:

- Because of gravity-like water in balloon-dependent edema accumulates and polyp tends to become wider at the bottom.

- Polyp is constrained by their anatomical boundaries and follows the path of least resistance into middle or inferior meatus. In this area, the bony constraints are no longer present, thus the distal end of polyp can enlarge, free of external pressure.

- The suction and the relative negative pressure generated by respiration, sneezing, and, particularly, swallowing may be of significance as an additional mechanical component.

Through the formation of thick, edematous body and of a long, thin neck a throttling effect may be created, which significantly inhibits retrogression of the polyp. 


\begin{tabular}{lll}
\hline \multicolumn{3}{c}{ Table 2: Percentage of cases with cystic origin } \\
\hline Studies & Number of cases & Percentage \\
\hline el-Guindy and Mansour & 4 & 100 \\
Berg et al & 24 & 100 \\
Özdek et al $^{3}$ & 15 & 60 \\
Aktaş et al $^{6}$ & 10 & 69 \\
Deka & 16 & 60 \\
Present study & 120 & 100 \\
\hline
\end{tabular}

According to studies in other series, the origins seem to be cystic (Table 2). ${ }^{3-6}$

We found that origin of the antrochoanal polyp is cystic in $100 \%$, similar to studies done by el-Guindy and Mansour ${ }^{4}$ and Berg. ${ }^{5}$

\section{Pathogenesis}

\section{Secretory Cysts}

According to Mills, ${ }^{7}$ pathogenesis of the cysts in all cases gave history of previous antral infection, and in many it has been proved by antral lavage; hence, it is thought that this is an important etiological factor. ${ }^{8}$

Probable course of events is as follows:

- A patient develops a suppurative maxillary sinusitis, the antrum being full of pus surrounded by an edematous mucosa. ${ }^{8}$

- The pus drains naturally through the ostium leaving the edematous mucosa.

- Most authorities now agree that cyst may be the origin of some antrochoanal polyp, but still refer to a single antral polypus being dragged through an accessory ostium, either from nearby or from the opposite wall. It has been suggested that cilia may carry out polypus into the nose, becoming nipped in the ostium, and then enlarging by edema, followed by cystic degeneration in the mass. A second alternative of polypus being pulled through the ostium during violent nose blowing has also been postulated.

\section{PROETZ'S THEORY}

Proetz suggested that the wide ostia which may be a result of faulty development may itself be the cause of antrochoanal polyp.

Cook et $\mathrm{al}^{1}$ reported allergic disease in approximately $70 \%$ of their patients in antrochoanal polyp.

Recent studies on etiopathogenesis have revealed some new finding. Jang et al studied the role of arachidonic acid metabolites in the pathogenesis of antrochoanal polyp and found that decreased lipoxygenase pathway products may be involved in pathogenesis of antrochoanal polyp.

Sunagawa et al showed possible role of urokinasetype plasminogen activator and plasminogen activator inhibitor-1 in the pathogenesis of antrochoanal polyp in their study.

\section{CLINICAL FEATURES ${ }^{11}$}

(1) Unilateral or bilateral nasal obstruction: nasal obstruction may be unilateral or bilateral, progressive continuous. (2) Headache/pain: it usually occurs over the bridge of the nose, the forehead, and cheeks. (3) Postnasal drip: it is usually white, but may become green or yellow, particularly with maxillary pains or following exacerbation of nasal symptoms. (4) Epistaxis: this is infrequent and follows extensive clearing of the nose. (5) Obstruction during sleep/snoring obstructive sleep apnea is reported due to antrochoanal polyp. (6) Nausea during eating and swallowing: due to large choanal part. (7) Loss of sensation of smell. (8) Running nose and sneezing. (9) No major symptoms. (10) Stridor: Rarely polyp may cause respiratory distress due to laryngeal obstruction and emergency tracheostomy may be required. (11) Nasal twang: hyponasal speech due to nasal mass.

\section{Signs}

If the polyp develops before the facial bone fuses, hypertelorism will develop in more florid cases. It is seen in children with cystic fibrosis.

\section{Anterior Rhinoscopy}

Anterior rhinoscopy will reveal smooth, large, single, grayish, mobile, pedunculated mass in middle meatus. Nasal part of polyp can undergo epithelial metaplasia into squamous type due to exposure and trauma and the surface becomes less glistening and the polyps appear white or pinkish in color.

Probe can be passed all around the polypus. Polyp is soft, mobile, and insensitive. They don't bleed on touch.

\section{Posterior Rhinoscopy}

Posterior rhinoscopy will reveal polypoidal mass present in choana. Mucopurulent or purulent discharge, congestion of nasal mucosa, tenderness over the sinuses may be elicited.

\section{Investigations}

- No specific hematological, biochemical, and immunological investigations.

- Polyps in early age-investigate for cystic fibrosis, ciliary dysfunction, and immune deficiency.

- Radiological investigations.

- Plain X-ray_sinus radiographs. Waters' view

- CT scans

- Diagnostic nasal endoscopy. 


\section{Differential Diagnosis}

It may be quite impossible to distinguish clinically between simple nasal polyps, polypoid lesions due to specific granulomatous diseases, and polypoid neoplasm. Rhinosporidiosis, inverted papilloma, angiofibromas, encephaloceles, carcinomas, and sarcomas.

\section{Histology}

Gross appearance: smooth surfaced, creamy, semi-translucent, dumb bell-shaped mass; microscopic appearance; nasal polyps usually have a respiratory epithelium with ciliated columnar epithelium with goblet cells. ${ }^{12}$

If there has been repeated trauma, squamous epithelial metaplasia occurs. The polyp consists of delicate edematous "loose" connective tissue, heavily vacuolated, and many dilated small blood vessels that are more numerous in the superficial parts of the polyp. Infiltration with plasma cells and few eosinophils is seen.

\section{Modified (“Mini”) Caldwell-Luc Procedure ${ }^{13}$}

Yanagisawa et $\mathrm{al}^{13}$ at Yale School of Medicine, New Haven, CT, coined the term "Mini" Caldwell-Luc.

\section{Advantages of this technique include}

- It is a direct telescopic approach to antral lesions.

- It allows easy decompression of the cystic mass and clear identification of the site of origin of the cyst.

- It allows the use of an elevator, such as Cottle or Coakley curette or a larger cup forceps allowing precise excision of the antral lesion.

\section{Disadvantages}

- A sublabial incision is required.

- Infraorbital hypoesthesia or anesthesia

- Slightly longer operative time needed

\section{Modified Caldwell-Luc}

The polyp and the antral mucosa are removed under direct visualization as one unit, thereby preventing any possibility for recurrence. ${ }^{14}$

The absence of a need to create a nasoantral window due to widened natural ostium further decreases the possibility of permanent dental sequelae. This is particularly true in the rare cases of antrochoanal polyp in children younger than 12 years in whom the canine and bicuspid tooth buds may still have not erupted.

\section{Management of Antrochoanal Polyp}

Awareness that antrochoanal polyp develops as an antral pathology and expands into nose as nasal component gives us a definite direction that both components must be removed totally. Any surgical technique leaving antral mucosal component will lead to recurrence. A total clearance of antral mucosa, which may be having microscopic intramural cyst, is essential for preventing the recurrence.

Killian (1906) could not remove the antral part of Killian's polyp by snare avulsion. Hence, there was recurrence.

Transcanine fossa approach (Ryan and Nee 1979) showed highly satisfying results with least recurrence, since this technique removed the complete diseased mucosa of the antrum. Interference with facial skeletal growth and damage to permanent dentition in children were major problems of this excellent technique. The possibility of damage to infraorbital nerve also becomes a concern of the technique. However, a carefully done Caldwell-Luc clearance of antrochoanal polyp in adult gives least complications in good hands. Secretion from sinus is always transported via the natural ostium, even when there is one or more accessory ostium in the area of the fontanelles and even in those patients in whom a patent window in inferior meatus has been surgically created. This is one of the reasons why no longer inferior meatal antrostomy is done. Aktaş et $\mathrm{al}^{6}$ have found that natural ostium had little tendency toward stenosis. This finding suggests that enlarging the natural ostium in the middle meatus is more effective and more physiological than fenestration in inferior meatus.

Endoscopic surgical technique to remove antrochoanal polyp to avoid the complications of Caldwell-Luc was welcomed by all. Transnasal endoscopic removal of antral component of polyp could not remove the diseased antral mucosa totally. Recurrence was noted in cases treated by this technique. This can only be due to inadequate removal of diseased antral mucosa. The advantages of minimal trauma and pain to patient were notable features in this technique, which was eclipsed by recurrence.

Transcanine sinuscopy and transnasal endoscopic facilities have given us "an insight" to blend the old and new technique.

In our study series, we were able to combine the old technique in a modified way with new endoscopic technique. The technique differed in adults and children.

In children, we made an inspection hole on canine fossa, which measured $<1 \mathrm{~cm}$. In adults, we approached the antrum by a bigger opening than that of children. The nasal component is gently mobilized at the pedicle. Endoscopic meatotomy of maxillary ostium helped us to deliver the antrochoanal polyp en bloc.

\section{Caldwell-Luc of Myer's and Cunnighan}

The availability of angled microdebrider and 45 endoscope will definitely help the endoscopic surgeon to 
clear the antral mucosa through the enlarged ostium of maxillary sinus. ${ }^{16}$

\section{Nasal Avulsion}

Studies done by

- Chen, el-Guindy and Mansour, ${ }^{4}$ and Kamel ${ }^{17}$ showed recurrence rate of $25 \%$.

- Mayo Clinic series showed recurrence rate of $20.3 \%$ of the 59 cases operated polyp.

- Heck in his series had recurrence rate of $28.2 \%$.

- Ryan and Nee had recurrence rate of $72 \%, 8$ out of 11 cases had recurrence.

Nasal avulsion had high rate of recurrence.

\section{Caldwell-Luc Surgery}

Studies done for Caldwell-Luc operation gave recurrence rate as follows:

- Schramm had recurrence rate of 3\%, one recurrence in 32 cases. Heck had recurrence rate of $5.5 \%$.

\section{Endoscopic Sinus Surgery}

Endoscopic transnasal approach appears to be better than the avulsion technique, but it also has recurrence.

\section{Intranasal Polypectomy}

\section{With Inferior Meatus Antrostomy}

- $\mathrm{Aktas}^{6}$ had recurrence rate of $50 \%$, recurrence in 4 of 8 operated cases; Gendeh et $\mathrm{al}^{16}$ had recurrence rate of $67 \%$, recurrence in 2 of 3 operated cases.

- Ophir and Marshak ${ }^{18}$ had no recurrence in their series of 12 cases.

\section{With Middle Meatus Antrostomy}

el-Guindy and Mansour ${ }^{4}$ had recurrence rate of $20 \%$, recurrence in 5 of 24 cases operated. Özdek et $\mathrm{al}^{3}$ had recurrence rate of $50 \%$, recurrence in 2 of 4 cases operated. Kaushal had recurrence rate of $15 \%$, recurrence in 3 of 20 cases. Balaba had recurrence rate of $50 \%$, recurrence in 3 of 6 cases operated. Ryan had recurrence of $4 \%$, recurrence in 1 of 21 cases. Gendeh et $\mathrm{al}^{16}$ had no recurrence in case series of 14 cases.

In a study by Atighechi et al, ${ }^{19} 19$ underwent endoscopic endonasal removal of polyp, out of which 4 cases had recurrence.

\section{Transcanine Approach}

- Ryan and Nee in case series of 14 cases had no recurrence.

- Özdek had no recurrence in 6 cases operated. Özdek et $\mathrm{al}^{3}$ performed FESS, combined FESS, and transcanine sinoscopy or Caldwell approach for treatment of antrochoanal polyp. They found recurrence in 3 patients after FESS, yet they found no recurrence after combined approach.

- Atighechi et $\mathrm{al}^{19}$ used combined approach with FESS. Out of 40 patients, 19 underwent endoscopic endonasal removal of polyp and 21 had combined approach. Out of 19 cases, 4 cases had recurrence, whereas Mini Caldwell group had no recurrence $(p=0.042)$. They reported minimal recurrence with Mini Caldwell approach and a low complication rate.

- Lee and Huang ${ }^{20}$ with transnasal endoscopic approach had success rate of $76.9 \%$, whereas combined approach had success rate of $100 \%$.

- In 20 cases of antrochoanal polyp who had undergone Mini Caldwell-Luc and endoscopic sinus surgery, no recurrence is seen during the period of follow-up, ranging from 5 to 30 months.

Studies done by Ryan and Nee, Özdek et al, ${ }^{3}$ Lee and Huang, ${ }^{20}$ Atighechi et $\mathrm{al}^{19}{ }^{19}$ and our study all had no recurrence.

\section{CONCLUSION}

Awareness that antrochoanal polyp develops as an antral pathology and expands into nose as nasal component gives us a definite direction that both components must be removed totally. Any surgical technique leaving antral mucosal component will lead to recurrence. A total clearance of antral mucosa which may be having microscopic intramural cyst is essential for preventing the recurrence.

So we conclude: (1) amalgamations of old and new technique with modification has given us least recurrences, (2) least trauma to facial skeleton, least damage to permanent dentition, (3) minimal postoperative pain and swelling, (4) minimum hospital stay.

\section{RECOMMENDATIONS}

A long-term follow-up of the cases is needed to rule out recurrence. To prevent recurrence, the antral part should be cleared of nidus of unhealthy mucosa. Mini Caldwell is a safe technique that exposes the antrum and its recesses. Endoscopy helps in clearance of osteomeatal complex and associated other sinus disease. Combination of both endoscopy and Mini Caldwell-Luc nullifies the disadvantages of individual procedure.

\section{ACKNOWLEDGMENTS}

The authors would like to thank Dr PY John for all the support and guidance. They also appreciate the help of other staff members of BLDE's Shri B. M. Patil Medical College, Bijapur, Karnataka, India. 


\section{REFERENCES}

1. Cook PR, Davis WE, McDonald R, McKinsey JP. Antrochoanal polyposis: a review of 33 cases. Ear Nose Throat J 1993 Jun;72(6):401-402, 404-410.

2. Deka RC. Antrochoanal polyp: its pathogenesis, origin, management by functional endonasal endoscopic surgery. Indian J Otolaryngol Head Neck Surg 1999 Jan;51(1):33-35.

3. Özdek A, Samim E, Bayiz Ü, Meral I, Şafak MA, Oğuz H. Antrochoanal polyps in children. Int J Pediatr Otorhinolaryngol 2002 Sep;65(3):213-218.

4. El-Guindy A, Mansour MH. The role of transcanine surgery in antrochoanal polyp. J Laryngal Otol 1994 Dec;108(12): 1055-1057.

5. Berg O, Carenfelt C, Silfverswärd C, Sobin A. Origin of the choanal polyp. Arch Otolaryngol Head Neck Surg 1988 Nov;114(11):1270-1271.

6. Aktaş D, Yetişer S, Gerek M, Kurnaz A, Can C, Kahramanyol M. Antrochoanal polyps: analysis of 16 cases. Rhinology 1998 Jun;36(2):81-85.

7. Mills CP. Secretory cyst of maxillary antrum and their relation to development of antrochoanal polyp. J Laryngol Otol 1959 May;73(5):324-334.

8. Majumdar B, Bull PD. The incidence and bacteriology of maxillary sinusitis in nasal polyposis. J Laryngol Otol 1982 Oct;96(10):937-941.

9. Jang YJ, Rhee CK, Oh CH, Ryoo HG, Kim HG, Ha M. Arachidonic acid metabolites in antrochoanal polyp and nasal polyp associated with chronic paranasal sinusitis. Act Otolaryngol. 2000 Jun; 120(4):531-534.

10. Sunagawa M, Kinjoh K, Nakamura M, Kosugi T. Urokinasetype plasminogen activator and plasminogen activator inhibitor antigen in tissue extracts of paranasal sinus mucous membranes affected by chronic sinusitis and antrochoanal polyps. Eur Arch Otorhinolaryngol. 1999;256(5):237-241

11. Drake-Lee AB, Lowe D, Swanston A, Grace A. Clinical profile and recurrence of nasal polyp. J Laryngol Otol 1984 Aug;98(8):783-793.

12. Kakoi H, Hiraide F. A histological study of formation and growth of nasal polyps. Acta Otolaryngol 1987 Jan-Feb; 103(1-2):137-144.

13. Yanagisawa E, Yanagisawa K, Fortgang P. Endosocpic excision of large benign antral lesion via modified ("mini") Caldwell-Luc procedure. Ear Nose Throat J 1995 Sep;74(9): 620-621.

14. Myers EN, Cunningham MJ. Modified Caldwell-Luc approach for treatment of antrochoanal polyps. Laryngoscope 1986 Aug;96(8):911-913.

15. Ryan RE Jr, Neel HB .Antral-choanal polyps. J Otolaryngol. 1979 Aug; 8(4):344-346.

16. Gendeh BS, Long YT, Misiran K. Antrochoanal polyp: clinical presentation and role of powered endoscopic polypectomy. Asian J Surg 2004 Jan;27(1):22-25.

17. Kamel R. Endoscopic transnasal surgery in antrochonal polyp. Arch Otolaryngol Head Neck Surg 1990 Jul;116(7):841-843.

18. Ophir D, Marshak G. Removal of antral polyp through an extended nasoantral window. Laryngoscope 1987 Nov;97(11): 1356-1357.

19. Atighechi S, Baradaranfar MH, Karimi G, Jafari R. Antrochoanal polyp: a comparative study of endoscopic endonasal surgery alone and endoscopic endonasal plus mini-Caldwell technique. Eur Arch Otorhinolaryngol 2009 Aug;266(8):1245-1248.

20. Lee TJ, Huang SF. Endoscopic sinus surgery for antrochoanal polyps in children. Otolaryngol Head Neck Surg 2006 Nov;135(5):688-692 